\title{
The Effect of Otago Exercise Program on Walking Speed and Fall Risk in Elderly Women
}

\author{
Lady Saerang, a, Subagyo ${ }^{\mathrm{a}}$, Nurul Kusuma Wardani ${ }^{\mathrm{a}}$, Soenarnatalina Melaniani ${ }^{\mathrm{b}}$
}

Corresponding author: dr.lady.saerang@gmail.com

aphysical Medicine and Rehabilitation Department, Faculty of Medicine Universitas Airlangga,

Dr. Soetomo Academic General Hospital, Surabaya, Indonesia.

${ }^{b}$ Department of Epidemiology, Demography Biostatistics and Health Promotion and Behaviour, Faculty of Public Health, Universitas Airlangga, Surabaya, Indonesia.

\begin{abstract}
Introduction: Elderly has a slower walking speed and an increased risk of falling. Decreased muscle mass and strength contribute to decreasing the ability to produce strength and accuracy responses to maintain balance and reduce walking speed. The Otago exercise program is a fall prevention exercise program for the elderly consist of lower limb strengthening exercises and balance exercises. This study aims to find the effects of eight weeks Otago exercise program on walking speed and risk of falling.

Methods: This research is pre and post-test randomized control group design. Twenty-six elderly women in nursing homes age 60 years old or more who meet inclusion criteria, divide into 2 groups, with thirteen subjects in each group. The intervention group performed the Otago exercise program 3 times a week for 8 weeks and the control group had no intervention. Ten meters walking test (10-mWT) is used to assess the walking speed and a timed up and go test (TUG) is used to assess fall risk. Walking speed and fall risk were assessed before and after the intervention.

Results: The results of this study showed that 8 weeks Otago exercise program significantly increase walking speed as assessed by the 10 -mWT test from $0.67 \pm 0.16 \mathrm{~m} / \mathrm{sec}$ to $0.79 \pm 0.19 \mathrm{~m} / \mathrm{sec}(\mathrm{p}<0.05)$ and significantly decreased the risk of falling by TUG test $14.99+2.82 \mathrm{sec}$ to $14.00+2.93(\mathrm{p}<0.05)$ but not in the control group.

Conclusion: The Otago exercise program for 8 weeks increased walking speed and decreased the risk of falling in elderly women.
\end{abstract}

Keywords: Otago exercise program; Elderly women; Walking speed; Fall risk; Indonesia.

\section{Introduction}

The elderly have slower walking speed than adults and walking speed decreases with age. Walking speed is reducing $1 \%$ per year since the age of 60 years. The gait in the elderly is a longer stance phase, shorter steps, slower walking speed, increased step variability. Changes in gait occur due to the aging process which is the result of a decrease in the function of the motor, sensory and central nervous systems. Walking is a physiological process that requires the coordination of these three systems. Disorders one of that system contribute to balance function, and balance disorders are associated with decreased walking speed in the elderly (Jimenez, 2017; Jeon et al., 2017; Xie et al., 2017; Osoba et al., 2019). Walking speed correlates with 
functional ability and balance and as a determining factor for potential rehabilitation needs as well as a tool for predicting falls (Fritz and Lusardi, 2009). Ten-meter walking test (10-mWT) is a test that using and recommended as a valid clinical assessment to assess walking speed in healthy and elderly individuals (Peel, 2013; Peters et al., 2013).

The elderly are prone to falls. Injuries from falls have major consequences for morbidity, loss of physical function and independence, mortality, and utilization of health services. A fall occurs when a person's center of gravity moves out of the plane of support and attempts to restore balance are insufficient, ineffective, or non-existent. The aging process causes a decrease in muscle mass and muscle strength. This condition reduced the ability to produce strength and accuracy responses to maintain balance. Loss of lower extremity strength, especially ankle dorsiflexion, hip abduction, and adduction, is an important factor in the risk of falling (Hazzard and Halter, 2009). Timed Up and Go (TUG) is a functional test to assess mobility, balance, and risk of falling (Nepal et al., 2019).

The Otago exercise program is a fall prevention exercise program for the elderly consisting of lower limb strengthening exercises and balance exercises as well as a walking program as a part of the Otago exercise program. The Otago exercise program that is carried out regularly and consistently will improve lower limb strength, balance, reduce the risk of falling, have independence, and a better quality of life (Campbell and Robertson, 2003; Cabellar et al., 2015; Shubert et al., 2018; ACSM, 2018).

\section{Methods and Materials}

This research was carried out at the Surabaya Indonesia nursing home in October - December 2020 pre and post-test randomized control group design. The study aimed to evaluate the effect of an 8-week Otago exercise program on walking speed and the risk of falls in elderly women in a nursing home. Research subjects were selected by cluster random sampling method. Twenty-six elderly female subjects who met the inclusion criteria: (1) an elderly woman, age 60 years old or more; (2) living in the nursing home at Surabaya; (3) able to ambulate independently without assistive devices; (4) hemodynamically stable; (5) having sufficient vision and hearing capacity to participate in the exercise (6) signing the consent form to be the subject of the study, and were not included in the exclusion criteria: (1) the subject had participated in regular strengthening exercises with weights in 1 month before; (2) fractured lower limbs that interfered with ambulation function; (3) have moderate to severe cognitive disturbance; (4) suffered from vertigo, were divided into the treatment group and the control group, with 13 subjects in each group. The walking speed was assessed by the 10-mWT test, and the risk of falling was assessed by the TUG test. The assessment was carried out 1 day before and 1 day after intervention. The intervention group performed the Otago exercise program for 8 weeks, frequency 3 times per week, with a total training time of \pm 30 minutes per session. The Otago exercise program consists of 5 types of strengthening exercises for lower limbs, 12 balance exercises, and a walking program designed for the elderly. The strengthening exercises used ankle weight with starting level based on the participant's ability to perform ten repetitions and increased gradually. The control group did not receive any exercise program but got an education about a healthy lifestyle with healthy diet and benefit of walking exercise regularly.

Statistical test using SPSS 23.0 with a significance level of $\mathrm{p}<0.05$. The parametric statistics were used if the data is normally distributed and non-parametric if the data is not normally distributed. Comparing the 10mWT and TUG values before and after treatment in each group, paired t-test was used if the data were normally distributed or the Wilcoxon Signed Rank Test was used if the data were not normally distributed. Comparing the difference between pre and post 10-mWT and TUG between the treatment and control groups, an unpaired t-test was used if the data were normally distributed or the Mann-Whitney test was used if the data were not normally distributed. The effect size of intervention was analyzed by Cohen's d test. 
Ethical eligibility has been obtained from the Ethics Committee for basic science/clinical research at the Faculty of Medicine, Universitas Airlangga Surabaya with number 241/EC/KEPK/FKUA/2020 dated October 1, 2020.

\section{Result}

The characteristics of the two groups were homogeneous (p-value > 0.05). Normality tests for age, weight, height, body mass index, 10 meters walking test values in both groups were normally distributed (pvalue > 0.05). The normality test of the timed up and go values in the control group was not normally distributed but in the treatment group, it was normally distributed (Table 1).

The mean of 10-mWT in the treatment group before being given Otago exercise was $0.67 \pm 0.16 \mathrm{~m} / \mathrm{sec}$ and the mean after being given exercise for 8 weeks was $0.79 \pm 0.19 \mathrm{~m} / \mathrm{sec}$. Based on the paired t statistical test, there was a significant increase in the $10-\mathrm{mWT}$ value in the treatment group $(\mathrm{p}=0.004)$. In the control group, the mean value of $10-\mathrm{mWT}$ at the initial assessment was $0.66 \pm 0.17 \mathrm{~m} / \mathrm{sec}$, and the mean value of $10-\mathrm{mWT}$ at the final evaluation was $0.65 \pm 0.18 \mathrm{~m} / \mathrm{sec}$. The results of the normality test for the final $10-\mathrm{mWT}$ value in the control group were not normally distributed and a non-parametric test with the Wilcoxon Signed Ranks Test did not show a significant increase in the $10-\mathrm{mWT}$ value in the control group $(\mathrm{p}=0.861)$ (Table 2$)$. The comparative analysis changes between groups by Mann-Whitney test showed significant differences $(p=$ 0.000) (Table 3). Cohen's d test mean effect size in the intervention group showed medium effect $(\mathrm{d}=0.6)$.

The mean TUG value of the treatment group before being given Otago exercise was $14.99 \pm 2.82$ seconds, and $14.00 \pm 2.93$ seconds after performed the Otago exercise program for 8 weeks. Based on the paired $t$ statistical test, there was an increase in the TUG value in the treatment group $(p=0.005)$. In the control group,

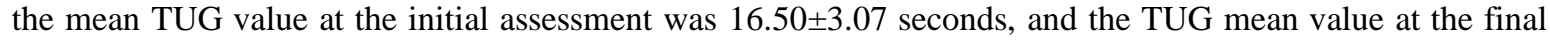
evaluation was $16.57 \pm 3.13$ seconds. Based on the normality test, the initial TUG value in the control group was not normally distributed, and a non-parametric test was performed with the Wilcoxon signed ranks test, there was no significant increase in the TUG value in the treatment group $(\mathrm{p}=0.328)$ (Table 4). The comparative analysis changes between groups by unpaired t-test showed significant differences $(p=0.003)$ (Table 5). Cohen's d test mean effect size in the intervention group showed a small effect $(\mathrm{d}=0.3)$.

Table 1. Baseline characteristics and homogeneity

\begin{tabular}{lccccc}
\multicolumn{1}{c}{ Variable } & $\begin{array}{c}\text { Intervention } \\
(\mathrm{n}=13) \\
\text { Mean } \pm \text { SD }\end{array}$ & $\begin{array}{c}\text { p-value } \\
\text { (normality) }\end{array}$ & $\begin{array}{c}\text { Control } \\
(\mathrm{n}=13) \\
\text { Mean } \pm \text { SD }\end{array}$ & $\begin{array}{c}\text { p-value } \\
\text { (normality) }\end{array}$ & $\begin{array}{c}\text { p-value } \\
\text { (homogeneity) }\end{array}$ \\
\hline Age (years) & $74.31 \pm 6.21$ & 0.347 & $75.31 \pm 9.01$ & 0.557 & 0.745 \\
\hline Body weight $(\mathrm{kg})$ & $45.72 \pm 9.04$ & 0.538 & $49.33 \pm 9.04$ & 0.598 & 0.365 \\
\hline Body height $(\mathrm{cm})$ & $148.85 \pm 5.91$ & 0.219 & $146.92 \pm 7.78$ & 0.417 & 0.485 \\
\hline BMI (kg/m2) & $20.56 \pm 3.33$ & 0.628 & $22.62 \pm 3.35$ & 0.802 & 0.130 \\
\hline 10-mWT pre (m/s) & $0.67 \pm 0.16$ & 0.998 & $0.63+0.15$ & 0.052 & 0.800 \\
\hline TUG pre (second) & $14.99 \pm 2.82$ & 0.475 & $16.50 \pm 3.07$ & 0.017 & 0.204 \\
\hline
\end{tabular}

Note: $\mathrm{BMI}=$ Body mass index; $10-\mathrm{mWT}=10$ meters walking test; $\mathrm{TUG}=$ Timed Up and Go 
Table 2. Ten meters walking test before and after intervention

\section{Intervention $(n=13) \quad$ Control $(n=13)$}

\begin{tabular}{ccccccc}
\hline & Before & After & p-value & Before & After & p-value \\
\hline 10-mWT (m/sec) & $0.67 \pm 0.16$ & $0.79 \pm 0.19$ & $0.004^{*}$ & $0.66 \pm 0.17$ & $0.65 \pm 0.18$ & $0.861^{\mathrm{a}}$
\end{tabular}

Note: $10-\mathrm{mWT}=10$ meters walking test; $*$ Significant if $\mathrm{p}$-value $<0.05 ;{ }^{\mathrm{a}}=$ Wilcoxon Signed Ranks Test

Table 3. Comparison 10-mWT changes between groups

\begin{tabular}{lccc}
\hline & Intervention $(\mathbf{n}=\mathbf{1 3})$ & Control $(\mathbf{n}=\mathbf{1 3})$ & p-value \\
\hline$\Delta$ 10-mWT (m/detik) & $0.11 \pm 0.11$ & $0.00 \pm 0.03$ & $0.000^{* \mathrm{~b}}$
\end{tabular}

Note: $10-\mathrm{mWT}=10$ meters walking test; $*$ Significant if $\mathrm{p}$-value $<0,05,{ }^{\mathrm{b}}=$ Mann-Whitney Test

Table 4. Timed up and go test before and after intervention

\section{Treatment $(n=13) \quad$ Control $(n=14)$}

\begin{tabular}{ccccccc}
\hline & Before & After & p-value & Before & After & p-value \\
\hline TUG (seconds) & $14.99 \pm 2.82$ & $14.00 \pm 2.93$ & $0.005^{*}$ & $16.50 \pm 3.07$ & $16.57 \pm 3.13$ & $0.328^{\mathrm{a}}$
\end{tabular}

Note: TUG $=$ Timed Up and Go test; $*$ Significant if $\mathrm{p}$-value $<0.05 ;{ }^{\mathrm{a}}=$ Wilcoxon Signed Ranks Test

Table 5. Comparison TUG changes between groups

\begin{tabular}{lccc} 
& Intervention $(\mathbf{n}=\mathbf{1 3})$ & Control $(\mathbf{n}=\mathbf{1 3})$ & p-value \\
\hline$\Delta$ TUG (seconds) & $-0.8 \pm 1.02$ & $0.07 \pm 0.32$ & $0.003^{*}$
\end{tabular}

Note: TUG= Timed Up and Go test; *Significant if $\mathrm{p}$-value $<0,05$

\section{Discussion}

Performed Otago exercise program for 8 weeks significantly increased walking speed as assessed by the $10-\mathrm{mWT}$ test. There was an increase in walking speed of $0.11 \mathrm{~m} / \mathrm{sec}$ in the treatment group with the effect size value based on the delta of the treatment group is 0.6 which indicates that the Otago exercise program has a moderate effect on increasing walking speed as assessed by the 10-mWT test.

The results of this study are in line with the research by Leem et al (2019), that reported either performed Otago exercise program alone or the Otago exercise program combined with action observation training for 12 weeks in elderly women, both groups found an increase in walking speed, cadence, step length, and stride. length as measured by the GAITRite system and the increased muscle strength of the thigh flexors, ankle dorsiflexors, and plantarflexors as measured by a dynamometer. Yoo et al (2013), reported that giving an Otago exercise program or a virtual-based Otago exercise program for 12 weeks to 21 elderly women, both groups had an increase in walking speed, cadence, stride length as measured by the GAITRite system and the 
berg balance scale.

Possible explanations for the effectiveness of 8 weeks Otago exercises program increased walking speed is mainly the effect of balance training which improves balance control and coordination systems so increased the walking speed. The exercises with walking backward, walking to form a figure 8, walking sideways, walking in tandem, and climbing stairs in the Otago training program trigger the activity of the thigh flexor muscles and ankle muscles leading to increased muscle strength and coordination, therefore, increased walking speed. In this exercise, the subject practices speed, distance, direction, rhythm, tone, and muscle strength when walking, increased coordination ability and body mass transfer through movements in the lower limbs and causes an increase in step length and stride length, thereby increasing walking speed and cadence (Yoo. et al., 2013; Leem et al., 2019). Parera et al (2006) reported a change in walking speed of 0.10 as a significant improvement and $0.05 \mathrm{~m} / \mathrm{s}$ as a minimum recommended value as a clinically significant threshold value. The increase in walking speed of $0.05 \mathrm{~m} / \mathrm{s}$ although small but still significant. In this study, the difference changes in walking speed in the treatment group were $0.11 \mathrm{~m} / \mathrm{sec}$, indicating that the 8 -week Otago exercise program was effective in increasing walking speed.

Performed Otago exercise program for 8 weeks reduced the risk of falling by decreased the TUG test in the treatment group by 0.99 seconds, while in the control group there was no decrease in the TUG time. The effect size value of the treatment group was 0.3 , indicating that the Otago exercise program had a small effect on reducing the risk of falling with the TUG test. The small effect size can be increased by extending the treatment time, according to a study by Kocic et al (2018) who reported an increase in TUG values after 3 months of Otago exercise and getting better after 6 months of Otago exercise. Caballer et al (2015), reported that giving Otago exercise with video guidance for 4 months resulted in a decrease in TUG values as functional balance. Shubert et al (2016), reported that giving Otago exercises to the elderly for 8 weeks in a multicenter study resulted in significant improvements in TUG scores, 30-second chair rise, and four-stage balance.

Possible explanations for the Otago exercise program reduced risk of falling by increased postural control in static and dynamic balance as a result of balance training with an increase in balance challenges that can improve balance control through movement strategies and dynamic control as well as increased muscle activation responses and increased muscle strength as a result of strengthening exercises. The balance exercises increasing ankle strategy and hip strategy in maintaining balance. The small effect size can be increased by extending the treatment time, according to a study by Kocic et al (2018), which reports an increase in TUG value after 3 months and getting better after 6 months of performed Otago exercise.

Lower limb strengthening exercises in the Otago training program focus on the main muscles of the lower limbs, that is the knee flexors and extensors, and thigh abductors, which play an important role in functional movement and walking. Strengthening the ankle dorsiflexors and plantarflexors plays an important role in restoring balance. The dynamic balance exercises in the Otago workout help maintain balance and increase the ability to restore balance. Pan increase in lower extremity strength and balance will ultimately reduce the risk of falling (Campbell and Robertson, 2003).

\section{Conclusion}

The Otago exercise program for 8 weeks increased walking speed and decreased the risk of falling in elderly women in a nursing home, therefore the Otago exercise program is recommended for elderly women to reducing the risk of falling and increasing walking speed. 


\section{References}

Caballer, V., Rosado-Calatayud, P., Segura-Ortí, E., Amer-Cuenca, JJ, \& Lisón, JF 2016. The effectiveness of a video-supported group-based Otago exercise program on physical performance in community-dwelling older adults: a preliminary study. Physiotherapy, 102(3), 280-286.

Campbell, AJ, \& Robertson, MC 2003. Otago exercise program to prevent falls in older adults. Wellington: ACC Thinksafe, 3.

Fritz, S., \& Lusardi, M. 2009. White paper: “walking speed: the sixth vital sign”. Journal of geriatric physical therapy, 32(2), 2-5.

Hazzard, WR, \& Halter, JB 2009. Hazzard's geriatric medicine and gerontology.

Jeon, M., Gu, MO, \& Yim, J. 2017. Comparison of walking, muscle strength, balance, and fear of falling between repeated fall group, one-time fall group, and nonfall group of the elderly receiving home care service. Asian nursing research, 11(4), 290-296.

Jimenez MC. 2017. Normal Changes in Gait and Mobility Problems in the Elderly. Phys Med Rehabil Clin N Am 28, p 713-725

Kocic, M., Stojanovic, Z., Nikolic, D., Lazovic, M., Grbic, R., Dimitrijevic, L., \& Milenkovic, M. 2018. The effectiveness of group Otago exercise program on physical function in nursing home residents older than 65 years: A randomized controlled trial. Archives of gerontology and geriatrics, 75, 112-118.

Leem, SH, Kim, JH, \& Lee, BH 2019. Effects of Otago exercise combined with action observation training on balance and gait in the old people. Journal of exercise rehabilitation, 15(6), 848

Nepal, GM, Basaula, M., \& Sharma, S. 2019. Inter-rater reliability of Timed Up and Go test in older adults measured by physiotherapist and caregivers. European Journal of Physiotherapy, 1-7.

Peel, N., Kuys, S., Klein. 2013. Gait Speed as a Measure in Geriatric Assessment in Clinical Setting: A Systematic Review. The Journal of Gerontology: Series A, Volume 68, Issue 1. Pp. 39-46.

Perera, S., Mody, SH, Woodman, RC, \& Studenski, SA 2006. Meaningful change and responsiveness in common physical performance measures in older adults. Journal of the American Geriatrics Society, 54(5), 743-749.

Peters, DM, Fritz, SL, \& Krotish, DE 2013. Assessing the reliability and validity of a shorter walk test compared with the 10-Meter Walk Test for measurements of gait speed in healthy, older adults. Journal of geriatric physical therapy, 36(1), 24-30.

Shubert, TE, Smith, ML, Jiang, L., \& Ory, MG 2018. Disseminating the Otago exercise program in the United States: perceived and actual physical performance improvements from participants. Journal of Applied Gerontology, 37(1), 79-98.

Yoo, HN, Chung, E., \& Lee, BH 2013. The effects of augmented reality-based Otago exercise on balance, gait, and falls efficacy of elderly women. Journal of physical therapy science, 25(7), 797-801. 